\title{
Cariogenicity induced by commercial carbonated beverages in an experimental biofilm-caries model
}

\author{
Rodrigo A. Giacaman ${ }^{1,2}$, Vanesa Pailahual ${ }^{1}$, Natalia Díaz-Garrido ${ }^{1}$
}

Correspondence: Dr. Rodrigo A. Giacaman

Email: giacaman@utalca.cl

\begin{abstract}
'Department of Oral Rehabilitation, Cariology Unit, University of Talca, Talca, Chile,

${ }^{2}$ Interdisciplinary Excellence Research Program on Healthy Aging (PIEI-ES), University of Talca, Talca, Chile
\end{abstract}

\section{ABSTRACT}

Objectives: Frequent consumption of sugars-containing carbonated beverages has been associated with caries, but the consequences on the dental biofilm remain unclear. The aim was to evaluate the effect of commercial carbonated beverages and their sugar-free version on enamel and dentine demineralization and on the cariogenic properties of Streptococcus mutans biofilms. Materials and Methods: Biofilms of S. mutans UA159 were grown on enamel and dentin slabs and exposed 3 times/ day for $5 \mathrm{~min}$, to a commercial cola or orange-flavored carbonated beverage or to their sugar-free version. Biofilms/slabs were recovered to assess biomass, viable microorganisms, protein content and polysaccharides. Demineralization was estimated by the variation of Knoop surface microhardness. Results: Exposures to the biofilm with sugars-containing carbonated beverages resulted in similar biomass, viable microorganisms, proteins, and polysaccharides than sucrose $(P<0.05)$. The sugar-free cola and orange-flavored drink showed lower effect on the biofilm, as compared with sucrose or their sugared version $(P<0.05)$. All of the products tested, included the sugar-free, showed higher demineralization than the negative control $(P<0.05)$. Conclusions: Sugars-containing carbonated beverages enhance cariogenic activity of $S$. mutans biofilms, comparable with sucrose. Sugar-free carbonated beverages also have a high demineralizing potential, without affecting biofilm properties.

Key words: Carbonated beverages, cariogenicity, dental caries, oral biofilm, soft drinks, Streptococcus mutans, sucrose

\section{INTRODUCTION}

According to the most recent conceptualization of its pathogenesis, dental caries may be considered as an ecological sugars-dependent dysbiosis caused by pathobionts. ${ }^{[1]}$ The frequent presence of dietary sugars causes an imbalance in the ecological equilibrium of the resident microorganisms of the dental biofilm leading to a $\mathrm{pH}$ drop and the subsequent demineralization of the hard dental tissues. ${ }^{[2]}$ In this scenario, sugars must be considered as the main causative factor of caries. Indeed, the essential role of sugars in caries etiology has been recently emphasized, stating that "sugars is the

\begin{tabular}{|l|l|}
\hline \multicolumn{2}{|c|}{ Access this article online } \\
\hline Quick Response Code: \\
\hline
\end{tabular}

only crucial factor that determines the caries process in practice." ${ }^{[3]}$ This research focuses on sugars-containing carbonated beverages and their cariogenic potential, including their "sugar-free" versions. These products are also thought to be important contributors for chronic diseases, such as overweight and obesity, ${ }^{[4]}$ diabetes, ${ }^{[5]}$ and cardiovascular diseases. ${ }^{[6]}$ In a time of spiking rates of obesity and diabetes worldwide, at an alarming level, sugars consumption is a matter of high concern for many disciplines, not only dentistry.

This is an open access article distributed under the terms of the Creative Commons Attribution-NonCommercial-ShareAlike 3.0 License, which allows others to remix, tweak, and build upon the work non-commercially, as long as the author is credited and the new creations are licensed under the identical terms.

For reprints contact: reprints@medknow.com

How to cite this article: Giacaman RA, Pailahual V Díaz-Garrido N. Cariogenicity induced by commercial carbonated beverages in an experimental biofilm-caries model. Eur $\mathrm{J}$ Dent 2018;12:27-35.

DOI: 10.4103/ejd.ejd_188_17 
Carbon dioxide-containing beverages, named as soft drinks, carbonated beverages, among many others, are one of the chief contributors to the increased sugars daily intake. ${ }^{[7]} \mathrm{A}$ high and increasing consumption of carbonated beverages has been reported worldwide. Between 1970 and 1996, per capita consumption of soft drinks increased $23 \%$ in the USA, ${ }^{[8]}$ which represents an increase of $13.2 \%-15.8 \%$ in the total amount of calories. ${ }^{[9]}$ It has been reported that soft drink consumption per person/year is 162 L. $^{[10]}$ Since soft drinks typically contain a high concentration of sucrose, glucose or fructose, all of them biofilm-fermentable carbohydrates, analyzing these beverages in terms of their cariogenic potential becomes relevant.

Although there is an irrefutable association between carbonated drink consumption and a high caries experience, reported in several clinical and epidemiological studies, ${ }^{[11-14]}$ there is a lack of clarity on the effect of soft drink consumption on the dental biofilm. A study reported some biochemical characteristics of human whole saliva and dental plaque resulting from the daily consumption of commercial sugary beverages. ${ }^{[15]}$ The results indicated that moderate consumption of a cola drink failed to produce distinct changes related with caries. Adding to the confusion, a milestone study from the 50s in hamsters showed that soda had the lowest decalcification potential, when compared with the rest of the foodstuffs under study. ${ }^{[16]}$

As a way to palliate the deleterious effect of sucrose in the diet and in particular in soft drinks, many commercial products have replaced sucrose for natural or artificial sweeteners. Thus, carbonated beverages without sugars or "sugar-free" are widely considered caries safe. Although some sweeteners, including some of those contained in sugar-free soft drinks could be non- or anticariogenic by themselves, ${ }^{[17]}$ in practice, these products are usually combined with other fermentable polysaccharides, such as maltodextrins or starches. It has been reported that commercial sweeteners would be less cariogenic than sucrose, ${ }^{[18]}$ but still retaining some considerable demineralization potential.

Given the scarce information available on the effect of carbonated beverages with or without sucrose on demineralization and on the dental biofilm, the purpose of this study was to determine the cariogenic potential of two of the most highly consumed commercial carbonated beverages in the world.
Likewise, we aimed to compare, side-by-side, the cariogenic potential of the sugars-containing with the sugar-free commercial versions of both products, in a relevant experimental caries model with Streptococcus mutans biofilms.

\section{MATERIALS AND METHODS}

\section{Experimental design}

A previously validated ${ }^{[19]}$ and modified ${ }^{[20]}$ experimental caries model with $S$. mutans biofilms was used for these experiments. Bovine enamel and dentin slabs served as substrates for $S$. mutans biofilm formation. To estimate demineralization, initial Knoop surface microhardness $\left(\mathrm{SH}_{\mathrm{i}}\right)$ was assessed on each enamel and dentin slab to compare with the values by the end of the experimental phase. Slabs were randomly arranged in seven treatment groups, as described below. Biofilms were exposed to the different treatments for $5 \mathrm{~min}, 3$ times/day. Culture medium was changed twice per day. At the end of the experimental phase of 4 days for enamel and three for dentin, biofilms were separated from the slabs to assess the following dependent variables: Biofilm biomass, viable bacterial, extra- and intra-polysaccharide production and the total amount of soluble proteins within the biofilms. Slabs were retrieved to evaluate demineralization occurred throughout the experiment. Biofilm acidogenicity was estimated by $\mathrm{pH}$ variations in the culture medium, before each medium replacement. The entire experiment was repeated twice with each condition in triplicate $(n=6)$.

\section{Enamel and dentin slab preparation}

Bovine incisors were obtained and disinfected with 5\% $\mathrm{NaOCl}$ and then stored in $0.9 \% \mathrm{NaCl}$, for no longer than 30 days until being used. Slabs $(4 \mathrm{~mm} \times 7 \mathrm{~mm} \times 1 \mathrm{~mm})$ of enamel, from the middle part of the crown, and of dentin, from the root portion, were prepared with a cutting machine (LECO VC50 Diamond Saw, Michigan, USA) and polished thoroughly polished. $\mathrm{SH}_{\mathrm{i}}$ was obtained by a row of three indentations on the slabs, $100 \mu \mathrm{m}$ apart from each other, with a Knoop microindenter with a microhardness tester (402 MVD, Wolpert Wilson Instruments, Norwood, USA) at $50 \mathrm{~g}$ for $5 \mathrm{~s}$ in enamel and $10 \mathrm{~g}$ for $5 \mathrm{~s}$ in dentin. To start the experiments in similar conditions and avoid variability, only enamel slabs with $\mathrm{SH}_{\mathrm{i}}$ of $364.19 \pm 36.4 \mathrm{~kg} / \mathrm{mm}^{2}(n=42)$ and dentin slabs with $\mathrm{SH}_{\mathrm{i}} 58.51 \pm 5.8 \mathrm{~kg} / \mathrm{mm}^{2}(n=42)$ were included. Dentin slabs were sterilized with ethylene oxide ${ }^{[21]}$ and enamel slabs in autoclave at $121^{\circ} \mathrm{C}$ for $15 \mathrm{~min}$. 


\section{Streptococcus mutans biofilm formation}

Two healthy young volunteers donated saliva in the morning of the $1^{\text {st }}$ day of the experiments. Pooled saliva was sterilized through ultrafiltration with filters of $0.22 \mu \mathrm{m}$ and treated for $30 \mathrm{~min}$ with a protease inhibitor cocktail. To enable $S$. mutans adhesion to the dental tissue for biofilm formation, slabs were covered with the sterile saliva, thus creating an acquired pellicle-like structure. ${ }^{[22]}$ Once treated with the saliva, slabs were placed in individual wells of a 24-well culture plate (Corning Costar, Lowell MA, USA) by a specially designed hanger made of orthodontic wire. Frozen samples of $S$. mutans UA159 were reactivated in brain heart infusion (BHI) agar with 1\% glucose (Merck, Darmstadt, Germany) at $37^{\circ} \mathrm{C}$ and $10 \% \mathrm{CO}_{2}$ for $18 \mathrm{~h}$. Culture optical density was adjusted at $0.8-1.0(600 \mathrm{~nm})$ and an aliquot of $100 \mu \mathrm{L}$ was transferred to $50 \mathrm{~mL}$ of $1 \%$ sucrose-supplemented BHI broth, homogenized and $2 \mathrm{~mL}$ of the inoculated medium transferred to each well of the 24-well plate. Slabs were placed in the wells to form the sucrose-induced biofilm at $37^{\circ} \mathrm{C}$ and $10 \% \mathrm{CO}_{2}$ for 8 h. ${ }^{[23]}$ After the initial biofilm formation, samples were transferred to wells containing $0.1 \mathrm{mM}$ glucose to allow biofilm maturation under a physiological basal glucose concentration ${ }^{[19]}$ for $16 \mathrm{~h}$ to complete $24 \mathrm{~h}$ of growth and maturation. Enamel and dentin slabs were exposed to the carbonated beverages and to the controls under study.

\section{Treatments}

Each slab and the biofilm associated was randomly allocated to one of the following treatments: $0.9 \% \mathrm{NaCl}$ (negative caries control), soda water (negative caries control), cola soft drink (Coca-Cola ${ }^{\circledR}$, The Coca-Cola Company, Atlanta, USA), a sugar-free cola soft drink (Coca-Cola Zero ${ }^{\circledR}$ ), orange soft drink (Fanta ${ }^{\circledR}$ ), a sugar-free orange soft drink (Fanta Zero ${ }^{\circledR}$ ) and 10\% sucrose (caries-positive control). The choice of using Coca-Cola ${ }^{\circledR}$ and Fanta ${ }^{\circledR}$ was made because both are among the top 10 most sold soft drinks in the world, present in every country and represent $31 \%$ of the market in the USA. ${ }^{[10]}$ Products tested here were those available in the Chilean market. To simulate a moderate ingestion pattern of soft drinks, treatments were applied 3 times / day (9:00 AM, 1:00 PM and 5:00 PM) for 5 min on each occasion by immersion in a well of a new 24-well plate containing $2 \mathrm{~mL}$ of the treatment, washed with $0.9 \% \mathrm{NaCl} 3$ times and relocated in the BHI medium supplemented with $0.1 \mathrm{mM}$ glucose. To simulate $\mathrm{pH}$-cycling conditions, like in the mouth, culture medium was changed twice per day, before the first and after the last treatment.
Treatment cycles were repeated until completion of the experiment.

\section{Biofilm acidogenicity}

The $\mathrm{pH}$-cycling model led to a lower $\mathrm{pH}$ in the spent medium by the end of the day, after the series of three beverage exposures, and a higher $\mathrm{pH}$ values after overnight culture in glucose-containing medium. These variations were registered to estimate acidogenicity from the $S$. mutans biofilms in response to the treatments. Thus, $\mathrm{pH}$ was measured twice daily in the triplicate wells using a microelectrode (HI 1083B, Hanna Instruments, Rumania) coupled to a portable $\mathrm{pH}$ meter (HI 9126-02, Hanna Instruments).

\section{Slab demineralization}

Loss of surface hardness ( $\mathrm{SH}$ ) has been extensively used as a reliable methodology to evaluate demineralization. ${ }^{[24]}$ Given that dentin is more prone to acid dissolution, the length of the experimental phase for dentin was shortened $24 \mathrm{~h}$. Slabs/biofilms were washed 3 times with $0.9 \% \mathrm{NaCl}$ and vortexed (Maxi Mix II tipo 37600 Mixer, Thermolyne, Iowa, USA) for $30 \mathrm{~s}$ to separate biofilms from the dental substrate. The resulting biofilm suspension was kept for further biofilm analysis. Final $\mathrm{SH}\left(\mathrm{SH}_{\mathrm{f}}\right)$ of the slabs was measured, in the same way as the $\mathrm{SH}_{\mathrm{i}}$ to estimate demineralization produced throughout the experimental period. A new set of three indentations was used to calculate the variation of $\mathrm{SH}$ occurred during the experiment. Mean values from the $\mathrm{SH}_{\mathrm{i}}$ and $\mathrm{SH}_{\mathrm{f}}$ were used to obtain the percentage of $\mathrm{SH}$ loss (\%SHL) calculated as: $\left(\right.$ mean $\mathrm{SH}_{\mathrm{i}}-$ mean $\left.\mathrm{SH}_{\mathrm{f}}\right) \times$ $100 / \mathrm{SH}_{\mathrm{i}}$.

\section{Characterization of the Streptococcus mutans biofilm exposed to the carbonated beverages}

Biofilm suspensions separated from the slabs were analyzed for biomass, viable bacteria, soluble proteins and extra and intracellular polysaccharide (IPS) production, as briefly described.

\section{Biomass}

Sample dry weights were used to assess biomass. ${ }^{[22]}$ $200 \mu \mathrm{L}$ from the biofilm suspension was transferred to preweighted tubes and incubated in $100 \%$ ethanol at $-20^{\circ} \mathrm{C}$ for $15 \mathrm{~min}$. The resulting suspension was centrifuged for $10 \mathrm{~min}$ at $10,000 \times g$ and $4^{\circ} \mathrm{C}$ (Heraeus Megafuge 16R, Thermo Fisher Scientific, Waltham, MA, USA). The pellet was washed with $500 \mu \mathrm{L}$ of $75 \%$ ethanol and centrifuged again. Biofilms were desiccated to obtain the dry weight in an incubator at $37^{\circ} \mathrm{C}$ for $24 \mathrm{~h}$ (MCO-19M, Panasonic, Osaka, Japan). 
To obtain biomass values, final weight was subtracted from the initial weight of each tube and expressed as $\mathrm{mg}$ per $\mathrm{mL}$ of biofilm suspension.

\section{Viable bacteria}

Serial dilutions in $0.9 \% \mathrm{NaCl}(\mathrm{v} / \mathrm{v})$ of the biofilm suspension were prepared and three drops $(20 \mu \mathrm{L}$ each) were seeded onto BHI agar culture medium, in duplicate. ${ }^{[19]}$ Plates were incubated anaerobically for $24 \mathrm{~h}$ at $37^{\circ} \mathrm{C}$ (MCO-19M, Panasonic) and colonies counted from the dilution that allowed better visualization of isolated colonies. Counting was made under a magnification lens $(\times 4)$, in the dilution that had at least 20 separated colonies. The number of individual colonies from each plate was corrected by the dilution factor and expressed as $\mathrm{CFU} / \mathrm{mg}$ of biofilm dry weight. ${ }^{[25]}$

\section{Biofilm soluble proteins}

An aliquot of $50 \mu \mathrm{L}$ of the biofilm suspension was treated with $2 \mathrm{M} \mathrm{NaOH}$ and incubated at $100^{\circ} \mathrm{C}$ for $15 \mathrm{~min}$. Final suspension was centrifuged at 10,000 $\times g$ for $10 \mathrm{~min}$ at $4^{\circ} \mathrm{C}$ and the supernatant was used to determine total protein concentration through the Bradford method. ${ }^{[26]}$ Protein concentration in each biofilm sample was assessed by a microplate reader at $595 \mathrm{~nm}$ (Biotek, ELx800, Winooski, Vermont, USA) and the results expressed as $\mu \mathrm{g} / \mathrm{mg}$ of biomass.

\section{Intra- and extra-polysaccharides}

The procedures to assess polysaccharide concentration in the biofilms were taken from previous reports. ${ }^{[27]} \mathrm{In}$ brief, three polysaccharide fractions were analyzed: soluble extracellular polysaccharides (SEPS), insoluble extracellular polysaccharides (IEPS), and IPS. A $200 \mu \mathrm{L}$ aliquot from the biofilm suspension was centrifuged at $10,000 \times g$ for $5 \mathrm{~min}$ at $4^{\circ} \mathrm{C}$ (Heraeus Megafuge 16R, Thermo Fisher Scientific) to determine SEPS from the supernatant. ${ }^{[25]}$ The remaining pellet was treated with $200 \mu \mathrm{L} 1 \mathrm{M} \mathrm{NaOH}$, homogenized and centrifuged to acquire IEPS from the supernatant. The pellet from the previous steps containing the IPS was incubated with $200 \mu \mathrm{L} 1 \mathrm{M} \mathrm{NaOH}$ for $15 \mathrm{~min}$ at $100^{\circ} \mathrm{C}$ and centrifuged $\left(10,000 \times g\right.$ for $5 \mathrm{~min}$ at $\left.4^{\circ} \mathrm{C}\right)$. The three supernatant fractions from each extraction step were separately treated with 3 volumes of cold $100 \%$ ethanol and incubated for $30 \mathrm{~min}$ at $-20^{\circ} \mathrm{C}$. Samples were immediately centrifuged and the resulting pellet was washed with cold $70 \%$ ethanol and centrifuged again $\left(10,000 \times g\right.$ for $5 \mathrm{~min}$ at $\left.4^{\circ} \mathrm{C}\right)$. The resulting pellet of each fraction was resuspended in $1 \mathrm{M} \mathrm{NaOH}$ and total carbohydrate concentration was estimated by the sulfuric phenol method, ${ }^{[28]}$ using a microplate reader (ELx800, Biotek) and the results were standardized by dry weight of biofilm and expressed as \% polysaccharide/mg of biomass.

\section{Statistical analysis}

Normal distribution of the data was verified and values obtained from the different treatment groups were compared by one-way analysis of variance followed by the post hoc Tukey test, using the Statistical Package for Social Sciences 15.0 software for Windows (IBM Corporation, NY, USA). Differences were considered significant at a $95 \%$ confidence level.

\section{RESULTS}

Biofilm acidogenicity induced by the carbonated beverages and measured by medium $\mathrm{pH}$ after each medium change is illustrated in Figure $1 \mathrm{~A}$ and $\mathrm{B}$, for enamel and dentin, respectively. At $32 \mathrm{~h}, \mathrm{pH}$ dropped notoriously in the biofilms treated with the sugary carbonated beverages Coca-Cola ${ }^{\circledR}$ and Fanta ${ }^{\circledR}$ $(P<0.0001)$, in enamel and dentin, similar to the caries-positive control. From this time-point onward, $\mathrm{pH}$ kept decreasing throughout the experiment. Acidogenicity induced by Soda water, Fanta Zero ${ }^{\circledR}$, and Coca-Cola Zero ${ }^{\circledR}$ remained similar to $0.9 \% \mathrm{NaCl}$, above 5.5.

Demineralization induced by all carbonated beverages and tested through \% SHL was higher than the negative control $(P<0.0001)$ [Figure 2-IA and B]. Fanta led to the highest demineralization among the treatments, higher than sucrose $(P<0.0001)$, but similar to Coca-Cola ${ }^{\circledR}$ [Figure 2-IA]. Sugar-free version of the beverages showed lower values than their sugars-containing counterparts $(P<0.05)$, but higher than soda water [Figure 2-IA]. Interestingly, soda water induced approximately 5\% more demineralization than $0.9 \% \mathrm{NaCl}$ on enamel $(P=0.025)$ and $30 \%$ on dentin $(P=0.001)$. Dentin showed high levels of demineralization with all the treatments assayed [Figure 2-IB], regardless of the sugars content of the soft drinks.

Similar to $10 \%$ sucrose, biofilms exposed to Fanta ${ }^{\circledR}$ and Coca-Cola ${ }^{\circledR}$ with sugars showed more biomass formation $(P<0.0001)$ than the other treatments [Figure 2-IIA and B]. In this regard, no differences were detected among sugar-free commercial carbonated beverages, soda water, and $0.9 \% \mathrm{NaCl}$ in either tissue.

The amount of viable bacteria within the biofilms after the experimental phase was assessed and compared 


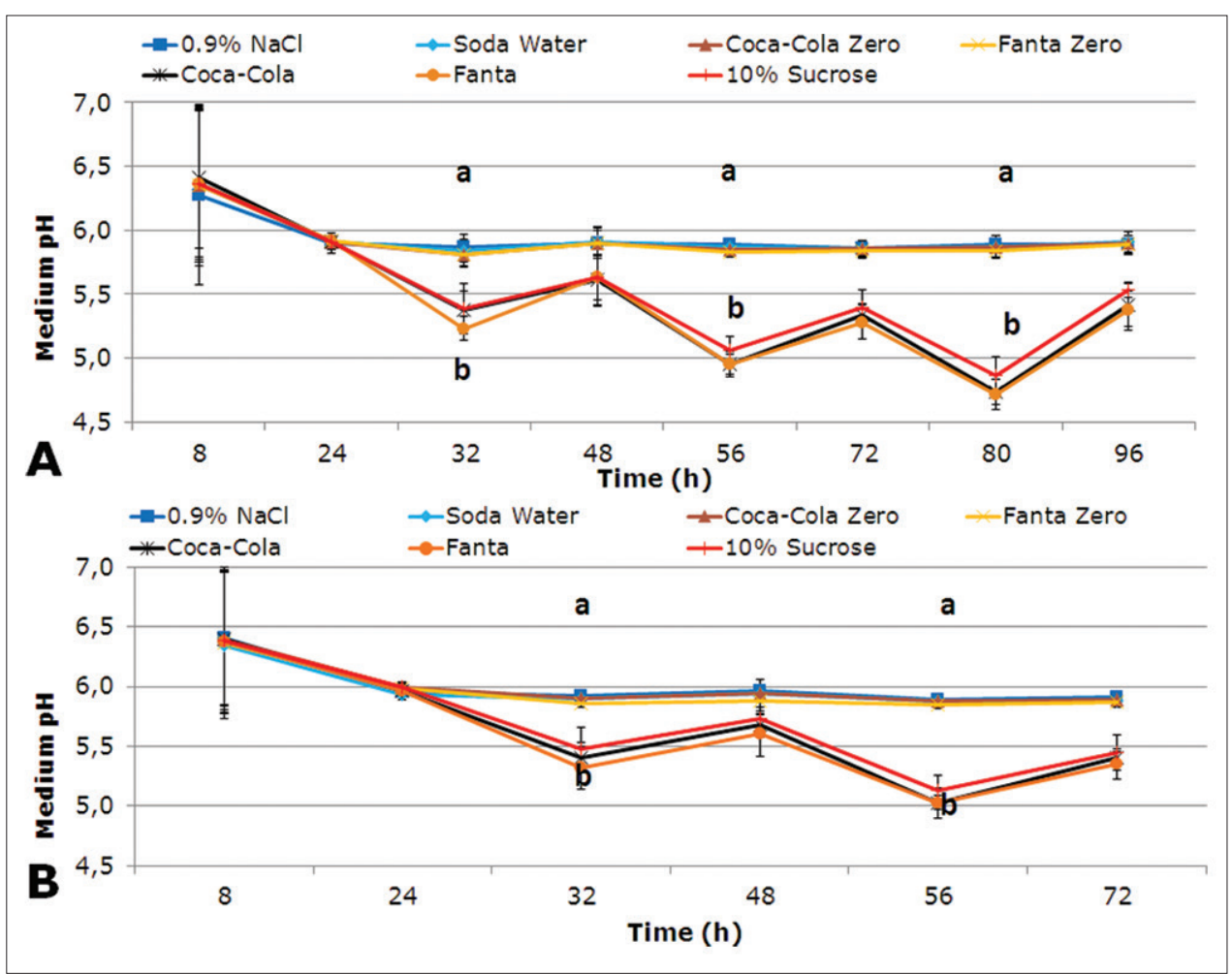

Figure 1: Acidogenicity from Streptococcus mutans biofilms formed on enamel (A) and dentin (B), exposed to tested carbonated beverages. Plot shows $\mathrm{pH}$ of the culture medium. Each point in the plot represents mean $\mathrm{pH}$ of 2 independent experiments in triplicate wells $(n=6)$. Error bars represent standard deviation. Different letters represent statistically significant differences among treatments $(P<0.05)$

among the different treatments. Exposure to the carbonated beverages Fanta ${ }^{\circledR}$ and Coca-Cola ${ }^{\circledR}$ induced the formation of biofilms with similar quantities of viable S. mutans cells to $10 \%$ sucrose and higher $(P<0.0001)$ than the other treatments. The sugar-free beverages were unable to induce bacterial proliferation, at least, at the level showed by the other commercial drinks. The same trend was observed in enamel [Figure 2-IIIA] and in dentin biofilms [Figure 2-IIIB].

Extracellular polysaccharide production by the biofilm in response to the carbonated beverages revealed that sugary drinks induced higher IEPS [Figure 2-IVA and B], SEPS, and total proteins (data not shown) than the sugar-free version, in a comparable level to that induced by sucrose. The same trend was verifiable in biofilms formed on enamel and dentin. In the case of the IPS, there was not a difference among any of the treatments in either dental tissue (data not shown), suggesting a lack of regulatory activity on this fraction induced by the nature of the beverage.

\section{DISCUSSION}

One of the most important sources of sucrose in the population is the consumption of carbonated beverages. ${ }^{[4]}$ In this context, the role of sugary foods, highly consumed by the population, is key to first understand the process and more importantly and to control its very high prevalence. A dose-dependent association between soft drink consumption and caries has been recently proposed. ${ }^{[12]}$ How these products modify the dynamic of the dental biofilm is less clear. This research, therefore, aimed to shed light on the mechanisms involved in the cariogenicity of some of the most consumed sugary drinks, included their sugar-free version. Our findings clearly showed that commercial carbonated beverages containing sucrose and presented to the biofilm at least 3 times/day were more cariogenic than those exposed to the sugar-free version. The choice of three daily exposures to the biofilm of soft drinks was based on a study that showed that daily between-meal consumption of at least 3 times associated with a 179\% increase in the probability of having high caries experience. ${ }^{[29]}$ Furthermore, a prospective 4-year study indicated that there may be a dose-response relationship between frequency of soft drink intake and increasing caries rates in adults, with 3 or more exposures representing a 33\% higher decayed, missing, or filled teeth as compared to those that reported no consumption. ${ }^{[12]}$

Sucrose concentration in the commercial carbonated beverages Coca-Cola ${ }^{\circledR}$ and Fanta ${ }^{\circledR}$ is $10.8 \%$ and $12.1 \%$, 


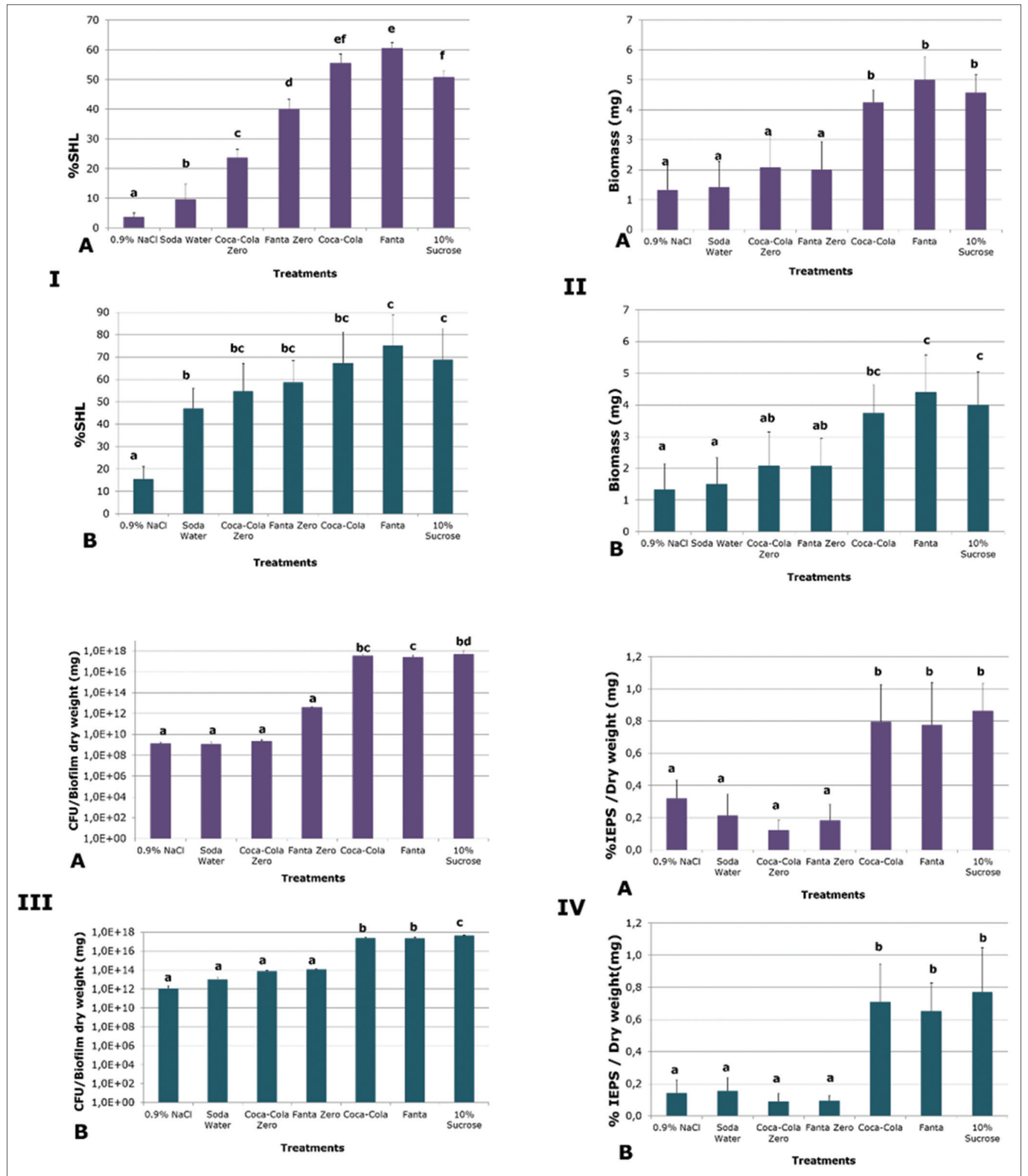

Figure 2: Effect of the different beverages tested on the outcomes of the study: Demineralization on enamel (A) and dentin (B). Bars represent mean percentage of surface hardness loss of the slabs. (II) Biomass induced by each experimental condition. Enamel (A) and dentin (B). Bars represent mean biomass (mg) obtained after exposure to each experimental condition. (III) Viable Streptococcus mutans cells in the biofilms formed on enamel (A) and on dentin (B). Bacterial cells retrieved from each biofilm exposed to test solutions were seeded on plates, counted and expressed as CFU/biofilm dry weight (mg). (IV) Insoluble extracellular polysaccharides produced by the biofilms in response to carbonated beverages. Enamel (A) and dentin (B) biofilms by the different conditions were measured and expressed as mg/mg of biofilm. Bars indicate mean values for each treatment. Error bars indicate standard deviation $(n=6)$. Different letters represent significant differences among treatments $(P<0.05)$ 
respectively. Given that both products contain a similar sucrose content to the caries-positive control $(10 \%)$, it was expected that both acted like sucrose control, in terms of cariogenicity. How can it be explained, then, that a commercial product that is labeled as containing no sugar added is capable to exhibit an important demineralizing potential? In fact, both Zero versions (sugar-free) of the commercial carbonated beverages showed significantly higher demineralization than the $0.9 \% \mathrm{NaCl}$ negative control [Figure 2-I]. The reason may arise from the acidity of the sugar-free soft drinks. Besides carbon dioxide, both products contain phosphoric and citric acids, according to the manufacturer [Table 1]. We measured the $\mathrm{pH}$ of the drinks before exposure to the biofilms and all of them had a $\mathrm{pH}$ below 3.5. Interestingly, the effect of the sugar-free carbonated beverages was only on the demineralization, without affecting the biomass, the number of bacteria, or the polysaccharide production. The latter strongly suggests a rather erosive potential of these acidic beverages. Once in contact with the dental biofilm, acid-containing soft drinks entail two different risks; first, sugars may lead to caries by acid production by the acidogenic microbiota with subsequent demineralization. On the other hand, acid content and low $\mathrm{pH}$ in the drink may cause erosion on the hard dental tissues. Erosion caused by acidic beverages has been widely discussed ${ }^{[30-32]}$ and it is still a growing field of study. Moreover, erosion derived from frequent acidic soft drink consumption has been associated with dentin hypersensitivity. ${ }^{[33]}$ Thus, sugar-free carbonated beverages must not be considered cariogenic, in the sense that they mediate the biological process of caries, but dangerous, as they can induce erosion and produce dentin hypersensitivity.

Sucrose promotes biofilm growth and proliferation, mainly through polysaccharide production. ${ }^{[34]}$ Given the sucrose content of the carbonated beverages assayed, it was reasonable to retrieve biofilms with similar values of total biomass, viable bacteria and polysaccharide formation, than those elicited with sucrose control. As expected, a carbonated sugar-free soft drink may exert its deleterious activity chemically, without interfering with the properties of the biofilm, like we reported here. In an in vivo situation, the effect of the sugar-free carbonated beverage may include alternative mechanisms, nonetheless. When the actual clinical biofilm is exposed to acidic soft drinks without sugars, many species may find hostile environmental conditions due to the low $\mathrm{pH}$, as shown here. Commensal microbiota may be impaired to outcompete aciduric microbiota, like $S$. mutans and others. These aciduric and acidophilic microorganism are endowed with a powerful regulatory machinery to withstand stressful and demanding conditions. ${ }^{[35]}$

One interesting finding was that $\mathrm{Fanta}{ }^{\circledR}$ induced higher demineralization than sucrose on enamel [Figure2-IA]. We believe that the explanation may be 2-fold. First, Fanta ${ }^{\circledR}$ contains more sucrose $(12.1 \%)$ than the caries-positive control (10\%), hence, an increased production of acids. On the other hand, and according to the manufacturer, Fanta ${ }^{\circledR}$ is made with modified starches as thickeners, unlike Coca-Cola ${ }^{\circledR}$. Those components may create a more viscous solution that is metabolized by the biofilm. It has been reported that starches enhance cariogenicity of sucrose, when both are combined and exposed to the biofilm. ${ }^{[27]}$ When starch derivatives, such as maltodextrins, are added to products containing noncariogenic sweeteners, the biofilm is yet capable to ferment and induce acid production. ${ }^{[18]}$

It is generally accepted that sparkling soda or soda water is harmless in terms of dental health and many dentists actually prescribe it as an alternative to sugars-containing carbonated beverages. We decided to use soda water as a control, so the sugar-free carbonated beverages could be compared with a

\begin{tabular}{|c|c|c|c|c|c|}
\hline Group & Treatment & $\begin{array}{l}\text { Identification or } \\
\text { commercial name }\end{array}$ & $\begin{array}{l}\text { Sucrose } \\
(\mathrm{g} / 100 \mathrm{~mL})\end{array}$ & Acid contained & $\mathrm{pH}^{*}$ \\
\hline 1 & Caries-negative control & $0.9 \% \mathrm{NaCl}$ & 0 & None & 7.08 \\
\hline 2 & Soda water & Soda water & 0 & Carbon dioxide & 4.84 \\
\hline 3 & Cola soft drink & Coca-Cola, Coke ${ }^{\circledR}$ & 10.8 & Carbon dioxide, Phosphoric acid, Citric acid & 3.02 \\
\hline 4 & Sugar-free cola soft drink & Coca-Cola Zero, Coke Zero ${ }^{\circledR}$ & 0 & Carbon dioxide, Phosphoric acid, Citric acid & 3.39 \\
\hline 5 & Orange soft drink & Fanta $^{\circledR}$ & 12.1 & Carbon dioxide, Phosphoric acid, Citric acid & 2.48 \\
\hline 6 & Sugar-free orange soft drink & Fanta Zero ${ }^{\circledR}$ & 0 & Carbon dioxide, Phosphoric acid, Citric acid & 3.14 \\
\hline 7 & Caries-positive control & $10 \%$ Sucrose & 10 & None & 5.80 \\
\hline
\end{tabular}


noncariogenic carbonated control and to estimate the demineralizing potential of carbon dioxide. Although demineralization induced by soda water in enamel was slightly higher than the negative control and lower than the Zero drinks [Figure 2-IA], in dentin, the demineralization was much higher than $0.9 \% \mathrm{NaCl}$ and similar to the sugar-free soft drinks [Figure 2-IB]. This result remarks the lower demineralization threshold of dentin ( $\mathrm{pH}$ 6.5) with regard to enamel ( $\mathrm{pH}$ 5.5). ${ }^{[36]}$ Based on the fact that the world is aging at a very high rate, root caries in this more susceptible population must be a concern. Gingival recession is common in older adults and is a risk factor for root caries. ${ }^{[37]}$ Hence, dietary counseling to older adults must take into account the higher susceptibility to root caries of this population and the hazard imposed by the consumption of carbonated soft drinks, including sugar-free versions and the erosive potential of soda water on root surfaces.

The high protein and polysaccharide [Figure 2-IV] production by the biofilms exposed to the carbonated beverages with sucrose is no surprise. Sucrose induces a mature biofilm by production of polysaccharides in a dose-dependent manner. ${ }^{[25]}$ The fact that the IPS did not show variation across the experimental groups suggests that these molecules are used only when bacterial cells are under severe starvation, as a reservoir for carbohydrates. ${ }^{[38]}$

We acknowledge the limitations of this in vitro approach. Alternative methodologies to assess demineralization may be used for further experiments, though microhardness has been extensively used to estimate demineralization in caries. A single-species biofilm, the absence of salivary proteins and salivary remineralizing ions, restrict drawing final conclusions. Yet, this methodological approach to test carbonated beverages overcomes obvious ethical limitations of an in vivo study and allows a better control of the variables, so commercial products can be compared in a side-by-side fashion. Further studies can contribute to expand these findings with alternative methodological strategies.

These results highlight the importance of controlling sugars consumption, especially due to the availability of sugars-containing soft drinks, their low prices, and their increasingly bigger volumes. For example, just one sugary drink contributes $295 \mathrm{kcal} /$ day, which represent about $35 \%$ of the sugars needed per day. ${ }^{[39]}$ Consumption of carbonated beverages has not decreased. A highly frequent consumption of these beverages create an ecological imbalance within the dental biofilm with loss of ecological balance leading to caries. ${ }^{[40]}$ On the other hand, it has been claimed that reducing consumption of free sugars below a threshold of $15-20 \mathrm{~kg} /$ person/year or $40-55 \mathrm{~g} /$ day or $10 \%$ of total energy intake) seems to result in a lower risk of caries. ${ }^{[41]}$ Unfortunately, most processed foods contain important amounts of added sugars and achieving this goal is not an easy task. Data between 1988 and 1994 from the "Third National Health and Nutrition Examination Survey" showed that carbonated beverages may have an cumulative effect after years of consumption. ${ }^{[14]}$

The multifactorial nature of the disease actually is under scrutiny, as the other involved factors, i.e., saliva, fluoride, tooth structure, socioeconomic status, among others, are not necessary factors for caries causation, but modifiers of the relationship of sugars and the dental biofilm. Hence, preventive measures should mainly consider the causative factors and secondarily the modifiers. In general, most of the energy is used to tackle the modifiers rather than the causative ones. Caries prevention must be oriented to control sugars consumption. Emphasizing on fluoride exposure or toothbrushing as the sole mechanisms to prevent caries will continue to fail, as the burden of disease clearly indicates. ${ }^{[42]}$ The dental profession, therefore, has an opportunity to integrate the multidisciplinary efforts to control diseases directly linked with sugars consumption, such as obesity and diabetes. Furthermore, other deleterious implications of sugar consumption are being considered. For example, sugars consumption has been associated with reduced white blood cell phagocytosis and inflammatory cytokine markers. ${ }^{[43]}$

\section{CONCLUSION}

Commercial sugary carbonated beverages seem to be as cariogenic as sucrose. The sugar-free versions may be less cariogenic than their sucrose-containing counterpart, albeit preserving a dangerous cariogenic and erosive potential. The cariogenic effect of these beverages on the biofilm appears to derive from both, the stimulating activity of sucrose on biofilm proliferation and also from the acidity of this type of soft drink, which increases demineralization of the hard tissues, particularly root dentin. This harmful activity may be enhanced by the common consumption pattern of high quantities and high frequency of the carbonated drinks. Preventive caries 
measures should take into account this risk and include recommendations on avoiding consumption, especially those containing sucrose.

\section{Financial support and sponsorship}

This study was supported by a Chilean Government Grant FONDECYT 1140623 to RAG.

\section{Conflicts of interest}

There are no conflicts of interest.

\section{REFERENCES}

1. Simón-Soro A, Mira A. Solving the etiology of dental caries. Trends Microbiol 2015;23:76-82.

2. Fejerskov O. Changing paradigms in concepts on dental caries: Consequences for oral health care. Caries Res 2004;38:182-91.

3. Sheiham A, James WP. Diet and dental caries: The pivotal role of free sugars reemphasized. J Dent Res 2015;94:1341-7.

4. Vartanian LR, Schwartz MB, Brownell KD. Effects of soft drink consumption on nutrition and health: A systematic review and meta-analysis. Am J Public Health 2007;97:667-75.

5. Malik VS, Popkin BM, Bray GA, Després JP, Willett WC, Hu FB, et al. Sugar-sweetened beverages and risk of metabolic syndrome and type 2 diabetes: A meta-analysis. Diabetes Care 2010;33:2477-83.

6. Malik VS, Hu FB. Sugar-sweetened beverages and health: Where does the evidence stand? Am J Clin Nutr 2011;94:1161-2.

7. Tahmassebi JF, Duggal MS, Malik-Kotru G, Curzon ME. Soft drinks and dental health: A review of the current literature. J Dent 2006;34:2-11.

8. Johnson RK, Frary C. Choose beverages and foods to moderate your intake of sugars: The 2000 dietary guidelines for Americans - What's all the fuss about? J Nutr 2001;131:2766S-71S.

9. Krebs-Smith SM. Choose beverages and foods to moderate your intake of sugars: Measurement requires quantification. J Nutr 2001;131:527S-35S.

10. Beverage-Digest. U.S. Beverage Business Results for 2014 March, 26; 2015. p. 66. Available from: http://www.beverage-digest.com/pdf/ top-10_2015.pdf. [Last accessed on $2016 \mathrm{Feb}$ 03].

11. Al-Haboubi M, Klass C, Jones K, Bernabé E, Gallagher JE. Inequalities in the use of dental services among adults in inner South East London. Eur J Oral Sci 2013;121:176-81.

12. Bernabé E, Vehkalahti MM, Sheiham A, Aromaa A, Suominen AL. Sugar-sweetened beverages and dental caries in adults: A 4-year prospective study. J Dent 2014;42:952-8.

13. Han DH, Kim DH, Kim MJ, Kim JB, Jung-Choi K, Bae KH, et al. Regular dental checkup and snack-soda drink consumption of preschool children are associated with early childhood caries in Korean caregiver/preschool children dyads. Community Dent Oral Epidemiol 2014;42:70-8.

14. Heller KE, Burt BA, Eklund SA. Sugared soda consumption and dental caries in the United States. J Dent Res 2001;80:1949-53.

15. Tenovuo J. Salivary parameters of relevance for assessing caries activity in individuals and populations. Community Dent Oral Epidemiol 1997;25:82-6.

16. Bibby BG, Goldberg HJ, Chen E. Evaluation of caries-producing potentialities of various foodstuffs. J Am Dent Assoc 1951;42:491-509.

17. Matsukubo T, Takazoe I. Sucrose substitutes and their role in caries prevention. Int Dent J 2006;56:119-30.

18. Giacaman RA, Campos P, Muñoz-Sandoval C, Castro RJ. Cariogenic potential of commercial sweeteners in an experimental biofilm caries model on enamel. Arch Oral Biol 2013;58:1116-22.
19. Ccahuana-Vásquez RA, Cury JA. S. mutans biofilm model to evaluate antimicrobial substances and enamel demineralization. Braz Oral Res 2010;24:135-41

20. Giacaman RA, Jobet-Vila P, Muñoz-Sandoval C. Fatty acid effect on sucrose-induced enamel demineralization and cariogenicity of an experimental biofilm-caries model. Odontology 2015;103:169-76.

21. Thomas RZ, Ruben JL, ten Bosch JJ, Huysmans MC. Effect of ethylene oxide sterilization on enamel and dentin demineralization in vitro. J Dent 2007;35:547-51.

22. Koo H, Hayacibara MF, Schobel BD, Cury JA, Rosalen PL, Park YK et al. Inhibition of Streptococcus mutans biofilm accumulation and polysaccharide production by apigenin and $\mathrm{tt}$-farnesol. J Antimicrob Chemother 2003;52:782-9.

23. Nascimento MM, Gordan VV, Garvan CW, Browngardt CM, Burne RA. Correlations of oral bacterial arginine and urea catabolism with caries experience. Oral Microbiol Immunol 2009;24:89-95.

24. Zero DT. In situ caries models. Adv Dent Res 1995;9:214-30.

25. Aires CP, Del Bel Cury AA, Tenuta LM, Klein MI, Koo H, Duarte S, et al. Effect of starch and sucrose on dental biofilm formation and on root dentine demineralization. Caries Res 2008;42:380-6.

26. Bradford MM. A rapid and sensitive method for the quantitation of microgram quantities of protein utilizing the principle of protein-dye binding. Anal Biochem 1976;72:248-54.

27. Duarte S, Klein MI, Aires CP, Cury JA, Bowen WH, Koo H, et al. Influences of starch and sucrose on Streptococcus mutans biofilms. Oral Microbiol Immunol 2008;23:206-12.

28. Dubois M, Gilles K, Hamilton JK, Rebers PA, Smith F. A colorimetric method for the determination of sugars. Nature 1951;168:167.

29. Ismail AI, Burt BA, Eklund SA. The cariogenicity of soft drinks in the United States. J Am Dent Assoc 1984;109:241-5.

30. Ehlen LA, Marshall TA, Qian F, Wefel JS, Warren JJ. Acidic beverages increase the risk of in vitro tooth erosion. Nutr Res 2008;28:299-303.

31. Fujii M, Kitasako Y, Sadr A, Tagami J. Roughness and $\mathrm{pH}$ changes of enamel surface induced by soft drinks in vitro-applications of stylus profilometry, focus variation 3D scanning microscopy and micro $\mathrm{pH}$ sensor. Dent Mater J 2011;30:404-10.

32. Owens BM, Kitchens M. The erosive potential of soft drinks on enamel surface substrate: An in vitro scanning electron microscopy investigation. J Contemp Dent Pract 2007;8:11-20.

33. Mafla AC, Lopez-Moncayo LF. Dentine sensitivity risk factors: A case-control study. Eur J Dent 2016;10:1-6.

34. Koo H, Xiao J, Klein MI. Extracellular polysaccharides matrix - An often forgotten virulence factor in oral biofilm research. Int J Oral Sci 2009;1:229-34.

35. Smith EG, Spatafora GA. Gene regulation in S. mutans: Complex control in a complex environment. J Dent Res 2012;91:133-41.

36. Melberg JR. Demineralization and remineralization of root surface caries. Gerodontology 1986;5:25-31.

37. Gregory D, Hyde S. Root caries in older adults. J Calif Dent Assoc 2015;43:439-45.

38. Busuioc M, Mackiewicz K, Buttaro BA, Piggot PJ. Role of intracellular polysaccharide in persistence of Streptococcus mutans. J Bacteriol 2009;191:7315-22.

39. Ervin RB, Ogden CL. Consumption of added sugars among U.S adults, 2005-2010. NCHS Data Brief 2013;122:1-8

40. Díaz-Garrido N, Lozano C, Giacaman RA. Frequency of sucrose exposure on the cariogenicity of a biofilm-caries model. Eur J Dent 2016; 10:345-50

41. Sheiham A, James WP. A reappraisal of the quantitative relationship between sugar intake and dental caries: The need for new criteria for developing goals for sugar intake. BMC Public Health 2014;14:863.

42. Kassebaum NJ, Bernabé E, Dahiya M, Bhandari B, Murray CJ, Marcenes W, et al. Global burden of untreated caries: A systematic review and metaregression. J Dent Res 2015;94:650-8.

43. Myles IA. Fast food fever: Reviewing the impacts of the Western diet on immunity. Nutr J 2014;13:61 